\title{
A EDUCAÇÃO DAS RELAÇõES ÉTNICO-RACIAIS EM ÂMBITO ESCOLAR: UMA ANÁLISE DAS CONCEPÇOES DE ALUNOS CONCLUINTES DO ENSINO FUNDAMENTAL ${ }^{1}$
}

\author{
THE EDUCATION OF ETHNIC-RACIAL RELATIONS IN SCHOOLS: AN ANALYSIS OF THE CONCEPTIONS OF \\ GRADUATING STUDENTS OF ELEMENTARY SCHOOL
}

\section{LA EDUCACIÓN DE LAS RELACIONES ÉTNICO-RACIALES EN ÁMBITO ESCOLAR: UN ANÁLISIS DE LAS CONCEPCIONES DE ALUMNOS CONCLUYENTES DE LA ENSENANZA FUNDAMENTAL}

\author{
MORERA, Cátia Silene2 ${ }^{2}$ \\ BILHÃO, Isabel ${ }^{3}$
}

\begin{abstract}
RESUMO
O artigo aborda as concepções de educação das relações étnico-raciais/ERER presentes nos depoimentos de alunas/os concluintes do Ensino Fundamental, a partir de suas trajetórias em duas escolas da rede municipal de São Leopoldo/RS. Objetiva-se compreender como os estudantes concebem a educação das relações étnico-raciais a partir das suas experiências escolares e refletir sobre o alcance da implementação da Lei 10.639/03 em âmbito local. Numa abordagem qualitativa, o estudo embasa-se na análise da legislação municipal para a ERER, em entrevistas com os supervisores pedagógicos e na aplicação de questionário as/os alunas/os. Como resultados, discutem-se limites e possibilidades de efetivação de uma educação das relações étnico-raciais nas escolas estudadas e identificam-se conhecimentos/reflexões construídos pelas/os estudantes sobre o tema com base em suas experiências escolares.
\end{abstract}

Palavras-chave: Educação das Relações Étnico-Raciais. Ensino Fundamental. Experiências Escolares.

\section{ABSTRACT}

The article deals with the conceptions of education of ethnic-racial relations/ERER present in the testimonies of students from the Elementary School, from their trajectories in two schools of the municipal network of São Leopoldo/RS. The objective is to understand how students conceive the education of ethnic-racial relations from their school experiences and reflect on the scope of the implementation of Law 10.639/03 locally. In a qualitative approach, the study is empirically based on the analysis of the municipal legislation for ERER, interviews with pedagogical supervisors and the application of a questionnaire to the students. As a result, we discuss limits and possibilities of effecting an education of ethnic-racial relations in the schools studied and identify the knowledge/reflections built by the students on the theme based on their school experiences.

Keywords: Education of Ethnic-racial Relations. Elementary School. School Experiences.

\section{RESUMEN}

El artículo aborda las concepciones de educación de las relaciones étnico-raciales/ERER presentes en los testimonios de alumnas/os concluyentes de la Enseñanza Fundamental, a partir de sus trayectorias en dos escuelas de la red municipal de São Leopoldo/RS. Se pretende comprender cómo los estudiantes conciben la educación de las relaciones étnico-raciales a partir de sus experiencias escolares y reflexionar sobre el alcance de la implementación de la Ley 10.639/03 a nivel local. En un abordaje cualitativo, el estudio se basa empíricamente en el análisis de la legislación municipal para ERER, en entrevistas con los supervisores pedagógicos y en la aplicación de cuestionario a las alumnas/os. Como resultados, se discuten límites y posibilidades de efectividad de una educación de las relaciones étnico-raciales en las escuelas estudiadas y se identifican conocimientos / reflexiones construidos por los estudiantes sobre el tema con base en sus experiencias escolares

Palabras clave: Educación de las Relaciones Étnico-raciales. Enseñanza Fundamental. experiencias escolares.

\footnotetext{
${ }^{1}$ A discussão apresentada nesse artigo é parte da Dissertação de Mestrado intitulada "A educação das relações étnico-raciais treze anos após a aprovação da lei 10.639/2003: estudo com base nas concepções dos estudantes concluintes do Ensino Fundamental (Rede Municipal de Ensino de São Leopoldo/RS)", realizada no PPGEDU da Universidade do Vale do Rio dos Sinos/UNSINOS.

2 Rede Municipal de Ensino São Leopoldo - São Leopoldo - Rio Grande do Sul - Brasil.

${ }^{3}$ Universidade do Vale do Rio dos Sinos - UNISINOS - São Leopoldo - Rio Grande do Sul - Brasil.
} 


\section{INTRODUÇÃO}

O artigo aborda as concepções sobre a educação das relações étnico-raciais presentes nos depoimentos de alunos concluintes do Ensino Fundamental/EF a partir de suas experiências em duas escolas da rede municipal de São Leopoldo/RS, no ano de 2016. A opção por realizar a investigação nesse município decorreu especialmente do fato de que a história da cidade, contada e comemorada nas escolas, vem privilegiando a noção de que São Leopoldo é o "berço da imigração alemã no Brasil" - em alusão ao estabelecimento de colonos alemães na região, em 1824. Tal perspectiva acabou tanto por eclipsar os conhecimentos escolares sobre o povoamento anterior, incluindo a existência de uma real feitoria que produzia linho-cânhamo para confecção de velas de embarcações - funcionando desde o século XVIII com mão de obra negra e escravizada - quanto colaborou para invisibilizar a participação de outros grupos étnicos na composição social e na constituição da cidade ${ }^{4}$. Nesse aspecto, nota-se o efeito contemporâneo da especial invisibilidade da presença da população afrodescendente nesse município. Some-se a essa justificativa, de caráter mais amplo, o fato de que a primeira autora desse artigo - por ser negra, ter nascido e vivido na cidade durante 35 anos, nela ter realizado sua formação escolar e universitária e atuar como professora da rede municipal de ensino observou muitas das questões ensejadas por essa narrativa sobre a história de São Leopoldo.

Outra justificativa para a abordagem desenvolvida nesse texto diz respeito à constatação de que embora a temática da educação das relações étnico-raciais/ERER venha sendo tratada por diversos estudos de distintas áreas acadêmicas ${ }^{5}$, em variadas perspectivas teóricas e metodológicas, observa-se ainda a pouca presença de análises sobre saberes/conhecimentos/reflexões construídos pelos estudantes sobre a ERER com base em suas experiências escolares. Portanto, ao procurar responder as indagações sobre as concepções apresentadas por estudantes da rede municipal de ensino de São Leopoldo, ao concluírem o EF, sobre a ERER e como a análise dessas formulações permite refletir sobre os avanços e limites, em âmbito local, da implementação da Lei 10.639/03, pretende-se colaborar para a ampliação de um aspecto que ainda tem comparecido pouco nessa discussão.

A investigação que embasou esse texto pautou-se, metodologicamente, pela análise da legislação para a ERER em âmbito municipal, pela realização de entrevistas com os coordenadores pedagógicos das escolas e pela utilização de questionário com os estudantes ${ }^{6}$. Quanto ao contexto

\footnotetext{
${ }^{4}$ Para mais informações sobre a Real Feitoria do Linho-Cânhamo, ver, entre outros: (JOHANN 2010). De acordo com o Censo do Instituto Brasileiro de Geografia e Estatística/IBGE, em 2010, São Leopoldo contava com uma população de aproximadamente 215.000 habitantes, constituída pelas mais diversas etnias e apresentando uma taxa de urbanização de $99,7 \%$. Portanto, não diferindo significativamente das demais cidades das regiões metropolitanas brasileiras em termos de composição populacional.

${ }^{5}$ Podendo-se mencionar, entre outros: Coelho e Soares (2016), Gomes (2012 e 2012a), Gomes e Jesus (2013), Munanga (2005), Santos (2012), Silva (2007).

${ }^{6}$ Quanto aos cuidados éticos: a proposta de investigação foi aprovada pelo Comitê de Ética em Pesquisa/ CEFUnisinos. Observaram-se os seguintes procedimentos: solicitação de autorização institucional para a realização da pesquisa, por meio de Carta de Anuência; esclarecimento dos objetivos e metodologia da pesquisa e da possibilidade de desistência em qualquer etapa do processo, por meio do Termo de Consentimento Livre e
} 
empírico, a seleção das escolas estudadas obedeceu a dois critérios: foram pré-selecionadas instituições que se localizam em bairros que apresentam alto contingente de pessoas que se autodeclaram negras $^{7}$, tendo como referência os dados do Censo do IBGE, de 2010 e, desse conjunto, foram delimitadas duas escolas pertencentes à rede municipal de ensino, selecionadas com base no Índice de Desenvolvimento da Educação Básica/IDEB. As escolas pesquisadas apresentam perfis distintos e suas identificações serão mantidas anônimas, sendo nomeadas como "Escola A" e "Escola B".

A Escola A é considerada de médio IDEB e se localiza no bairro Fazenda São Borja, na zona sudeste da cidade. De acordo com o Censo de 2010, o bairro abriga 2.555 habitantes e, destes, 12,6\% se autodeclaram negros. Segundo informações da Prefeitura Municipal, esse bairro possui uma das mais baixas densidades populacionais do município, especialmente por ser composto por uma Zona Rural e por Áreas de Preservação Ambiental e Urbana. O bairro se destaca ainda por abrigar várias empresas de grande porte (SÃO LEOPOLDO, 2006). A Escola A funciona nesse bairro desde 1975. A partir de 1996 passou a ofertar Educação de Jovens e Adultos/EJA e a partir de 2001, foram implantados os anos finais do EF. Atualmente a escola apresenta três turmas de $9^{\circ}$ ano, contabilizando aproximadamente 90 alunos concluintes do EF.

A Escola B é considerada de baixo IDEB e se localiza no bairro Santos Dumont, na Zona Norte do município. Composto essencialmente por área urbana, o bairro apresenta média densidade populacional para os padrões leopoldenses. Nesse bairro se encontram os lotes com os valores comerciais mais baixos da cidade (SÃO LEOPOLDO, 2006) e, segundo o Censo de 2010, nele residem 24.543 pessoas, das quais $18,4 \%$ se autodeclaram negras. A Escola B foi construída em 2008 em virtude do loteamento da região, impulsionado pela expansão da linha do trem urbano. Atualmente a Escola B conta com duas turmas concluintes do EF, totalizando aproximadamente 70 alunos.

Em relação às categorias analíticas que contribuíram para a interpretação dos dados produzidos, destacam-se as noções de "currículo" como campo de disputas, significados e construções sociais, especialmente a noção de "currículo oculto", de Tomaz Tadeu da Silva (2003) e "currículo turístico", de Jurjo Torres Santomé (2009). Com base nessa opção teórico-metodológica e visando responder às questões apresentadas, o artigo está organizado em dois tópicos. No primeiro, apresenta-se uma síntese das características da legislação municipal sobre a ERER e, com base nas entrevistas realizadas com os supervisores escolares, reflete-se sobre a implementação da legislação no contexto das escolas pesquisadas. No segundo tópico, analisam-se, a partir dos questionários respondidos pelos alunos concluintes do EF, os conhecimentos e percepções sobre a ERER, construídos com base em suas vivências escolares.

Esclarecido, assinado pelos entrevistados, pais ou responsáveis e do Termo de Assentimento assinado pelos estudantes; compromisso em manter o anonimato dos participantes e das instituições e de utilizar os dados apenas para finalidades científico-acadêmicas.

7 Ao fazer a análise dos dados, o IBGE soma as categorias "pardo" e "preto" formando um grupo denominado "negros" que inclui todas aquelas pessoas que se consideram afrodescendentes. 


\section{APROXIMAÇÕES E DISTANCIAMENTOS: A ERER NA LEGISLAÇÃO E NAS ESCOLAS}

Nesse tópico busca-se refletir sobre as características de implementação da ERER nas escolas estudadas. Inicia-se por uma breve contextualização da legislação municipal decorrente da aprovação da Lei 10639/20038 e do Parecer 03/2004 do Conselho Nacional de Educação/CNE, que instituiu as Diretrizes Curriculares Nacionais para a Educação das Relações Étnico-Raciais e para o Ensino de História e Cultura Afro-Brasileira e Africana/DCNERER. Na sequência apresentam-se excertos de relatos do trabalho desenvolvido nas escolas, a partir das entrevistas com os supervisores e finaliza-se com algumas reflexões sobre aproximações e distanciamentos entre texto legal e experiências escolares com base nas noções de currículo acima mencionadas.

A Lei $n^{\circ} 6.116$, de dezembro de 2006, foi a primeira sancionada em São Leopoldo, atendendo à determinação da legislação federal. Ela tornou obrigatória a inserção das DCNERER no currículo da rede pública municipal, acrescentando às determinações da lei nacional a obrigatoriedade do ensino da história afro-riograndense e afro-leopoldense e nominando as disciplinas que devem tratar da temática: Língua Portuguesa, Estudos Sociais (como eram chamadas na época as disciplinas de História e Geografia nos anos iniciais), Ciências e Educação Religiosa (SÃO LEOPOLDO, 2006).

A Lei 6.116/2006 determinou ainda que a qualificação dos professores da rede pública municipal e o constante aperfeiçoamento pedagógico exigido para implementação das DCN-ERER fiquem a cargo do Poder Executivo Municipal, que deve promover cursos, seminários e debates com a participação da sociedade civil, mais especificamente do movimento negro; intercâmbio com organismos nacionais e internacionais voltados à valorização do negro e a permanente avaliação de materiais didáticos e bibliográficos, a fim de suprir as carências identificadas.

Em 2010, o Conselho Municipal de Educação/CME emitiu a Resolução no 9 dispondo sobre os procedimentos para o desenvolvimento das diretrizes curriculares relativas à ERER e ao ensino da história e cultura afro-brasileira, africana e indígena, no Sistema Municipal de Ensino de São Leopoldo9. Essa Resolução estabeleceu que as escolas devem contemplar, em seu Projeto Político Pedagógico, referências de combate ao racismo e à discriminação, incluindo atividades que possibilitem o reconhecimento da importância da diversidade para a construção de relações étnico-raciais democráticas. O documento pretende ainda comprometer o grupo de profissionais das escolas a assumir sua parcela de responsabilidade para que se efetive o direito à diversidade e o respeito às diferenças. Segundo o texto: "É inaceitável que diante destas atitudes [preconceituosas e discriminatórias] se suavize a situação, se desconsidere a queixa daquele que se sentiu agredido, se aceite que tudo não passou de uma brincadeira" (SÃO LEOPOLDO, 2010, p. 7).

\footnotetext{
${ }^{8}$ Que modifica a redação da LDB 9.394/96, acrescentando-lhe os artigos 26-A, que estabelece a obrigatoriedade do ensino da história e cultura africana e afro-brasileira no Ensino Fundamental e Médio, e 79-B, que inclui no calendário escolar o dia 20 de novembro como o Dia Nacional da Consciência Negra (BRASIL, 2003a).

${ }^{9}$ Levando em consideração a promulgação de Lei 11645/2008 que altera a Lei no 9.394/1996, modificada pela Lei no 10.639/2003 e estabelece as diretrizes e bases da educação nacional, para incluir no currículo oficial da rede de ensino a obrigatoriedade da temática "História e Cultura Afro-Brasileira e Indígena".
} 
Dois anos após o lançamento dessa Resolução, foram publicadas as Orientações Curriculares para a Educação Básica da Rede Municipal de Educação de São Leopoldo. Nelas, se postula que a vida seja tomada como princípio central, levando à recusa de todas as formas de violência, aí incluídas as práticas de racismo e discriminação étnico-cultural. Essa concepção demanda, segundo o documento, "ações pedagógicas, que envolvam o conhecimento da história das referidas culturas, o respeito a elas, tanto pelo educador quanto pelo educando, bem como o combate ao racismo e às discriminações de qualquer natureza" (SÃO LEOPOLDO, 2012, p. 7).

Ao analisar as Orientações Curriculares, no entanto, percebe-se a falta de objetivos específicos de estudos das relações étnico-raciais e do ensino da história e da cultura afro-brasileira e africana na área de Ciências, conforme estabelecido pela Lei 6.616/2006. Além dessa ausência, observa-se ainda que áreas como Língua Portuguesa e Artes apresentaram poucos espaços de reflexão sobre essas temáticas.

Em 2015, foi promulgado o Plano Municipal de Educação de São Leopoldo, apresentando metas educacionais para o período de 2015 a 2024. Dentre essas, observa-se a meta sete, que objetiva fomentar a qualidade da Educação Básica em todas as etapas e modalidades, com melhoria do fluxo escolar e da aprendizagem, de modo a atingir as médias do IDEB projetadas para São Leopoldo. Uma das estratégias para alcançá-las é: garantir, nos currículos escolares, conteúdos sobre história e cultura afro-brasileira e realizar ações educacionais colaborativas, assegurando a implementação das DCN-ERER, por meio de parcerias com fóruns de educação para a diversidade étnico-racial, conselhos escolares, equipes pedagógicas e sociedade civil (SÃO LEOPOLDO, 2015).

Percebe-se, portanto, que, de forma semelhante ao que vem ocorrendo em âmbito nacional, produziu-se no município um volumoso aparato normativo e orientador, buscando induzir ao cumprimento da legislação para a ERER ${ }^{10}$. A leitura desse conjunto de textos indica que muito do que foi proposto baseia-se no diagnóstico de problemas e na intenção de sua superação. A aprovação da legislação ocorreu em momentos políticos favoráveis às demandas dos movimentos sociais e à pressão de parte da opinião pública que reconhece a legitimidade e a premência da questão. Entretanto, o texto legal nem sempre leva em consideração a realidade escolar e as condições em que se dá a implementação da legislação.

Cabe mencionar que o termo implementação, por si, remete a uma das fases do denominado "ciclo de políticas", estudado por Stephen Ball e Richard Bowe. Embora não esteja ao alcance desse artigo aprofundar essa discussão, é interessante observar que para esses autores a implementação caracteriza-se pelo momento em que a política é colocada "em uso", ou seja, quando os textos sancionados sofrem interpretações e recriações, produzindo consequências que ocasionarão os (re)desenhos da política original:

A questão é que os autores dos textos políticos não podem controlar os significados de seus textos. Partes podem ser rejeitadas, selecionadas, ignoradas, deliberadamente mal entendidas, etc. Além disso, interpretação é uma questão de disputa. Interpretações diferentes serão contestadas, uma vez que se relacionam com interesses diversos, uma ou outra interpretação

\footnotetext{
${ }^{10}$ No caso nacional: as Leis 10.639/2003 e 11645/2008, as DCNERER/2004 e o Plano Nacional de Implementação das DCN-ERER, de 2009.
} 
predominará, embora desvios ou interpretações minoritárias possam ser importantes (BOWE et al., 1992, p. 22, apud MAINARDES, 2006, p. 53).

Entretanto, essas disputas em torno da legislação, e seu (re)desenho no momento da implantação, não são vistos pelos autores como "problemas" a serem corrigidos mas sim como parte da dinâmica de estabelecimento das políticas nas diferentes realidades. Para o caso dessa investigação, o diálogo estabelecido com as escolas pautou-se por esse entendimento. Ao entrevistar os supervisores pedagógicos não se buscou identificar "problemas" de implementação da ERER nas escolas e sim compreender como as complexas relações cotidianas influem no (re)desenho, nos alcances e limites dessa legislação em um contexto multifacetado, por vezes conflituoso, e cambiante.

A opção por entrevistar os supervisores pedagógicos antes de apresentar os questionários aos alunos concluintes amparou-se na definição de suas atribuições. Segundo o Plano de Cargos e Carreiras dos Trabalhadores em Educação de São Leopoldo, esse profissional deve "planejar, orientar, coordenar, avaliar, assessorar e supervisionar as atividades pedagógicas em apoio ao trabalho desenvolvido nas unidades escolares" (SÃO LEOPOLDO, 2008, p. 4). A supervisora da Escola A é licenciada em Letras/Português. É docente há vinte e seis anos e trabalha na Escola A desde 2006, inicialmente como professora de Língua Portuguesa; de 2010 a 2013 como vice-diretora e, a partir 2014, atuando como supervisora pedagógica nos turnos da manhã e da tarde e como professora de Língua Portuguesa, na EJA, à noite. O supervisor da Escola B é licenciado em História e tem Especialização em Estudos Africanos e Afro-brasileiros, trabalha como docente desde 2012, sempre na escola B, e tornou-se supervisor pedagógico em 2013.

O ponto de partida para a formulação do roteiro preliminar que orientou as entrevistas foi a leitura da legislação acima apresentada. Mas, durante os contatos com os entrevistados, agregaram-se novas questões conforme suas perspectivas e análises. Uma das primeiras observações, formulada por ambos, é a de que haveria muita resistência por parte de professoras e professores em relação à Lei 10.639/2003. Solicitou-se então que opinassem sobre o porquê desta resistência. A supervisora da Escola A considerou que a Lei não é efetivamente implementada porque não há, por parte da SMED/SL, uma cobrança de que as escolas construam alternativas pedagógicas para a educação das relações étnico-raciais. Para o supervisor da Escola B a resistência estaria ligada ao entendimento de alguns professores de que o racismo seria um tema muito incômodo e potencialmente gerador de conflitos e que, portanto, seria melhor evitá-lo. Em suas palavras: "Pra muitos parece que, se tu não tocar no tema, não vai existir racismo. Muitos não conseguem entender que o racismo é estrutural' (SUPERVISOR, Escola B, 08/09/2016) ${ }^{11}$.

Quando questionados sobre a formação continuada e sobre as possíveis demandas da escola à SMED/SL para a realização dessa formação, a supervisora da Escola A relatou já ter participado, como supervisora, de oficinas que tratavam do tema da ERER, entretanto, não se lembrava de ter participado de nenhuma formação específica como professora. O supervisor da Escola B destacou que, ao longo do ano de 2014, a SMED/SL, em parceria com a Universidade Federal do Rio Grande do Sul/UFRGS, proporcionou uma formação extremamente significativa, baseada em palestras e leitura de

${ }^{11} \mathrm{O}$ tom coloquial, próprio da narrativa oral, foi mantido em todas as transcrições literais. 
textos, mas que poucos professores foram contemplados. Ambos responderam que em nenhum momento foi demandada à SMED/SL, por parte das escolas, realização de formação sobre a temática.

Em relação ao fornecimento de materiais didáticos e paradidáticos, a supervisora da Escola $A$ mencionou que a SMED/SL e o MEC enviam regularmente materiais e que nunca foi necessário solicitá-los à Secretaria. Não houve, no entanto, nenhum detalhamento sobre esses materiais e nem sobre as formas de sua utilização. O supervisor da Escola B mencionou a existência de muitos livros de literatura infantil com a temática que eram utilizados principalmente com os anos iniciais do EF. O supervisor citou ainda o conjunto de materiais denominado "A Cor da Cultura"12, composto por vídeos, Compact Disc, jogos e livros com fundamentação teórica para docentes. Entretanto, criticou a falta de formação continuada para a utilização desses materiais.

Quando questionados sobre a existência de diálogo para a implementação da Lei 10.639/2003 entre a SMED/SL e as escolas e entre as escolas e o movimento negro ou com a sociedade civil organizada, a supervisora da Escola A, mencionou que poderia haver mais diálogo entre a Secretaria e a escola, pois a rede municipal de ensino é constituída por um considerável número de instituições, e algumas delas desenvolvem projetos que abordam a temática. Segundo ela, a Escola A não mantinha diálogo sobre a Lei 10.639/2003 com o movimento negro ou com a sociedade civil leopoldense. Já o supervisor da Escola B percebia haver um esforço da Secretaria para manter o diálogo com as escolas a fim de implementar a Lei e de incentivar os profissionais a participarem das formações propostas e mencionou uma palestra realizada por um professor, militante do movimento negro, para os docentes da escola, por iniciativa da equipe diretiva, no ano de 2016.

Em relação à adequação dos projetos político pedagógicos/PPP das escolas, visando o ensino de história e cultura afro-brasileira e africana, a supervisora da Escola A disse que a Lei 10.639/2003 já constava no PPP, mas que não era trabalhada na escola. Segundo ela, porque não havia cobrança por parte da SMED/SL para que isso ocorresse. A fiscalização seria, em seu entendimento, um indutor para sua efetivação. Na escola B, o supervisou relatou que as questões relacionadas à Lei 10.639 estavam sendo incorporadas naquele momento ao PPP, mas que já havia na escola um grupo de professores que vinha discutindo e trabalhando as questões em sala de aula, mesmo antes dessa adequação do Projeto. Ou seja, na escola em que a Lei estava contemplada no Projeto não havia trabalho efetivo e na escola em que havia algum trabalho, a legislação ainda não havia sido incorporada ao documento.

Ao comentarmos a atualização e inserção, no Plano de Estudo e nos Planos de Trabalho, das alterações necessárias para o ensino dos conteúdos previstos nas DCN-ERER, a supervisora da Escola A relatou que houve a atualização da documentação, no entanto, não houve atualização das práticas pedagógicas. Segundo ela, seu desejo de realizar um trabalho sistematizado sobre a temática que culminasse em uma exposição no mês de novembro nunca se concretizou devido à resistência dos professores. Ainda segundo a supervisora, as poucas práticas pedagógicas realizadas na escola não aconteceram de forma autônoma, mas sim a partir da lembrança de que existe uma lei que torna obrigatório o ensino de história e cultura africana e afro-brasileira. O supervisor da Escola B também

\footnotetext{
12 Mais informações sobre o projeto "A Cor da Cultura” em: http://www.acordacultura.org.br. Último acesso: $22 / 01 / 2018$.
} 
relatou que, mesmo havendo uma reformulação nos planos de curso e de trabalho, não houve uma reformulação da prática da maioria dos colegas. Segundo ele: "o pequeno grupo de professores que já simpatizava com essa discussão trabalha a temática em sala de aula, e o restante fica acomodado, pois sabe que aqueles vão fazer o trabalho necessário" (SUPERVISOR, Escola B, 08/09/2016).

A última pergunta questionava se as escolas conseguiam construir, coletivamente, alternativas pedagógicas para a educação das relações étnico-raciais com suporte de recursos didáticos adequados. A supervisora da Escola A mencionou que acreditava ser algo possível, mas reiterou que os professores reclamavam da necessidade de trabalhar muitos conteúdos e que a Lei 10.639/2003 seria mais uma questão a ser incluída: "[...] o professor diz 'ah, mas além de tudo que eu tenho que trabalhar tem mais essa questão ainda', então, assim, às vezes aquilo vai perdendo a força e a gente não consegue realizar aquilo que a gente gostaria" (SUPERVISORA, Escola A, 06/09/2016).

O supervisor da Escola B mencionou tentativas esporádicas de construção de alternativas pedagógicas coletivas para a educação das relações étnico-raciais. Para ele, um dos limites da escola seria a inexistência de um processo contínuo de trabalho coletivo. Em sua narrativa, "perto de novembro, há uma tentativa coletiva. Agora, durante o ano, individual, individual, e é uma característica não só da Lei 10.639, é uma característica de qualquer projeto pedagógico da escola".

Esse conjunto de respostas pode ensejar uma série de reflexões sobre as características do cotidiano escolar, para o caso dessa análise interessa-nos refletir sobre algumas questões relacionadas mais especificamente com as noções de currículo como um campo de disputas em permanente (re)criação. Para Tomaz Tadeu da Silva (2003), "o currículo oculto é constituído por todos aqueles aspectos do ambiente escolar que, sem fazer parte do currículo oficial, explícito, contribuem, de forma implícita, para aprendizagens sociais relevantes" (SILVA, 2003, p. 78). Dessa forma, o não dito, "a voz oculta", ensina sobre diversas esferas sociais, como aqueles ligados à nacionalidade, gênero, sexualidade ou raça.

Ao longo da entrevista, em diferentes momentos, os supervisores comentaram como as práticas pedagógicas sobre a temática acabam por acontecer apenas no mês de novembro, momento em que se celebra o Dia da Consciência Negra. Esse tipo de abordagem da temática pode levar a propostas de trabalho que, segundo Jurjo Torres Santomé, configurariam o "currículo turístico", ou seja, aquele realizado com base "em unidades didáticas isoladas, nas quais esporadicamente, se pretende estudar a diversidade cultural" (SANTOMÉ, 2009, p. 173). Segundo o autor, com isso corre-se o risco de que "situações sociais silenciadas que normalmente se colocam como situações problemáticas na sociedade concreta na qual se encontra a escola (as etnias oprimidas, as culturas nacionais silenciadas, as discriminações de gênero, de idade, etc.) passem a ser contempladas, mas a partir de perspectivas de distanciamento" (SANTOMÉ, 2009, p. 173). Esse distanciamento colabora para que a temática étnico-racial seja tratada de maneira trivial, na qual a população negra é estudada com grande superficialidade, em uma pequena unidade, disciplina ou data determinada. Como no restante do ano letivo, essa realidade é silenciada, quando não atacada, desconectam-se, assim, as situações de diversidade da vida cotidiana das salas de aula, colaborando-se para a produção do "currículo oculto". 
No próximo tópico, pretende-se refletir sobre as concepções de ERER e os conhecimentos sobre a história e cultura afro-brasileira e africana construídos pelos alunos concluintes do EF de ambas as escolas, levando-se em consideração essas reflexões sobre currículo.

\section{SABERES, CONHECIMENTOS E REFLEXÕES: COMO O CURRÍCULO É SIGNIFICADO PELOS ESTUDANTES?}

Ao final do ano letivo de 2016 retornou-se às escolas estudadas e solicitou-se aos estudantes concluintes do EF que respondessem a um questionário elaborado com base nos conteúdos apresentados nas DCNERER. Dos noventa e um estudantes aptos, duas alunas da Escola B optaram por não responder. Dos 89 questionários entregues, 18 retornaram, ou seja, 19,8\% do total. As questões foram organizadas em três tópicos: relações étnico-raciais, conteúdos referentes à história e cultura africana e afro-brasileira e reflexão sobre a participação da população negra na história e cultura da sociedade brasileira.

No tópico relações étnico-raciais foram propostas três perguntas. Na primeira - Como você avalia seu contato com a história e cultura dos povos africanos e do povo afro-brasileiro ao longo da sua trajetória escolar? - todos os estudantes mencionam que tiveram contato em diferentes graus. $66,7 \%$ dos adolescentes consideram que tiveram pouco contato e $33 \%$ responderam que estudaram estas temáticas muitas vezes. Na segunda questão: Você recorda de ter conversado na escola sobre as imagens de negros apresentadas em novelas, revistas ou filmes? Aproximadamente $70 \%$ dos estudantes responderam que sim e $27,7 \%$ dos estudantes afirmaram que esse tema nunca foi discutido. Na terceira questão: Você recorda de ter realizado alguma atividade envolvendo pessoas negras de fora da escola? Aproximadamente $70 \%$ dos estudantes lembram-se de alguma atividade relacionada ao Dia da Consciência Negra em que houve a participação de pessoas negras que não faziam parte do quadro de professores ou funcionários. Entretanto, um terço dos estudantes não recorda de nenhum evento que tivesse esse caráter.

Ao analisar esse conjunto de respostas, pode-se supor que a realização de ações pedagógicas que contribuíssem para a reflexão sobre a presença da população negra na mídia não foi uma unanimidade na vida escolar dos estudantes. Da forma semelhante, pode-se concluir que participação de pessoas negras como protagonistas nos eventos escolares tenha ocorrido especialmente em atividades realizadas em alusão ao Dia da Consciência Negra, configurando um "currículo turístico".

O segundo tópico abordou conteúdos referentes à história e cultura africana e afro-brasileira. A questão foi assim proposta: Sobre os temas listados abaixo, assinale aqueles que você lembra de ter estudado. O quadro abaixo fornece, na primeira coluna, a listagem dos itens apresentados aos estudantes e, na segunda coluna, a sistematização das respostas. 


Quadro 1: Sistematização dos conteúdos referentes à História e Cultura Africana e Afro-Brasilei
\begin{tabular}{|c|c|}
\hline $\begin{array}{c}\text { Tráfico e escravidão } \\
\text { Acordos entre África, Brasil e outros países } \\
\text { da diáspora }\end{array}$ & 78 \\
\hline $\begin{array}{c}\text { Ancestralidade e religiosidade } \\
\text { Civilizações núbias e egípcias }\end{array}$ & 8 \\
\hline Reinos (Mali, Congo e Zimbábwe) & 2 \\
\hline Ocupação colonial & 3 \\
\hline Independência africana & 5 \\
\hline $\begin{array}{c}\text { Diáspora (cultura, história, diversidade e } \\
\text { relação com o continente africano) }\end{array}$ & 10 \\
\hline União africana & 4 \\
\hline
\end{tabular}

Fonte: elaborado pelas autoras

O tema mais lembrado pelos adolescentes como estudado ao longo de sua escolarização tráfico e a escravidão - confirma a ênfase que a temática vem recebendo nos currículos escolares, especialmente na disciplina de História do Brasil, e remete à crítica realizada pelo movimento negro ao destaque dado apenas a esse aspecto das vivências históricas da população negra em nosso país. Entretanto, pode-se supor também que o currículo escolar não seja o único e talvez nem o principal responsável pelo impacto desse conteúdo na memória dos estudantes. Uma hipótese do porquê da referência tão significativa à temática é o fato do período escravista aparecer reiteradamente em novelas, minisséries e outros programas televisivos assistidos pelos alunos - que raramente mostram as pessoas negras no pós-abolição - permitindo-Ihes atribuir maior significado ao tema quando tratado na escola ${ }^{13}$.

Retomando-se a reflexão de Tomaz Tadeu da Silva sobre o currículo como "prática cultural e de significação" (1999), pode-se pensar que ao se depararem com uma listagem de conteúdos sobre história e cultura africana e afro-brasileira, os estudantes atribuem sentido apenas a alguns deles, por estarem inseridos em uma determinada compreensão do mundo social, tornando-os inteligíveis. Diante disso, se torna compreensível que os estudantes atribuam mais significados e, portanto, assinalem mais "tráfico e escravidão" do que, por exemplo, "civilizações núbias e egípcias", assunto que tem sido apresentado apenas nos livros didáticos.

\footnotetext{
${ }^{13}$ Uma discussão sobre a construção da identidade negra nas telenovelas pode ser vista em (GRIJÓ e SOUSA, 2011).
} 
O terceiro tópico propunha uma reflexão sobre a participação da população negra na história e cultura da sociedade brasileira, a partir da pergunta: $O$ que você pensa sobre a participação da população negra na cultura e na história da sociedade brasileira? No quadro abaixo as respostas estão sistematizadas com base nas "ideias fortes" apresentadas pelos alunos.

\section{Quadro 2 - Sistematização da reflexão sobre a participação da população negra na história e cultura} da sociedade brasileira

\begin{tabular}{|l|l|}
\multicolumn{1}{|c|}{ Ideias fortes } & \multicolumn{1}{c|}{ Número de ocorrências } \\
\hline Vitimização da população negra & 4 \\
\hline Abaixo o preconceito & 3 \\
\hline $\begin{array}{l}\text { Necessidade de mais discussão } \\
\text { A população negra tem problemas de } \\
\text { auto aceitação }\end{array}$ & 3 \\
\hline $\begin{array}{l}\text { Todos somos humanos e temos os } \\
\text { mesmos direitos }\end{array}$ & 5 \\
\hline
\end{tabular}

Fonte: elaborado pelas autoras

A primeira constatação realizada com base nas respostas dissertativas é a de que a maioria dos estudantes não respondeu o que foi solicitado na pergunta, ou seja, não apresentou exemplos de participação da população negra na história e na cultura da sociedade brasileira. Essa discrepância pode estar relacionada a vários fatores, entre eles, a dificuldade de leitura e interpretação da questão por parte dos alunos, a não adequação da redação aos padrões vocabulares dos estudantes ou ainda à possibilidade de que estes, de fato, ainda não consigam atribuir nenhum protagonismo à população negra com base em suas vivências escolares.

A proposição que mais apareceu nas respostas é a de que "todos somos humanos e temos os mesmos direitos", alinhada à condenação ao racismo, aos preconceitos étnicos e às atitudes discriminatórias em geral. As respostas procuravam enfatizar que "ser negro é normal" e que a ação frente à população negra deve estar baseada na "normalidade". Nessa argumentação, o "anormal" seria o tratamento que difere brancos e negros. Entretanto, não se pode ignorar que o discurso da "normalidade" também é construído por diversos meios e que ele contribui para que as especificidades relacionadas à população negra sejam encobertas ou negadas, levando, por exemplo, à condenação de políticas de ação afirmativa, questão que também deveria ser discutida e problematizada na escola.

As respostas enfatizaram ainda a "vitimização" associada à "heroicização" da população negra", remetendo novamente ao tráfico, à escravidão, à violência e aos abusos sofridos. Em alguns casos foram mencionadas as formas de resistência, as lutas e as negociações que aconteciam entre a população negra escravizada e a população branca. 
Uma das respostas destoou do conjunto e pode ensejar uma reflexão para além do que havia sido incialmente proposto na questão. "Penso que existe um grande preconceito entre os brancos em relação aos negros, mas um preconceito maior dos negros, pois muitos não se aceitam como são. Mas, respondendo a pergunta [...]'. Esse estudante fez questão de assinalar que concorda com a existência do racismo no Brasil, mas que é necessário enfatizar que a população negra tem problemas de autoaceitação. Essa resposta expõe uma noção profundamente arraigada no senso comum da população brasileira, que, ao declarar a não autoaceitação da população negra, deixa de refletir sobre o porquê desse fenômeno e de certa forma minimiza o preconceito de parte da população branca. Novamente, se poderia refletir sobre as possíveis problematizações que, em âmbito escolar, desnaturalizariam essa interpretação, discutindo-se, por exemplo, as formas de constituição da identidade étnica em um país que apresenta um discurso dominante da superioridade étnico-racial branca que afeta toda a população.

\section{CONSIDERAÇÕES FINAIS}

Esse artigo não pretende propor conclusões passiveis de generalização, sua intenção foi, ao contrário, estabelecer reflexões com base no estudo de contextos escolares específicos sobre algumas características do processo de implementação da ERER. Acredita-se que a importância dessa abordagem esteja justamente em seu caráter microanalítico, ou seja, no sentido de que ela permite ajustar o foco para compreender os desafios, avanços e limites, em âmbito local, dos efeitos de macro políticas.

Assim, pode-se destacar o fato de que São Leopoldo - município marcado pela construção de uma memória de apologia à colonização alemã e de invisibilização da participação de outras etnias na constituição da cidade - produziu um volumoso aparato legislativo visando adequar a rede municipal de ensino às demandas da Lei 10.639/2003 e das DCNERER/2004. Salienta-se a questão de que a legislação municipal apresentou em várias partes do texto o reconhecimento de problemas relacionados ao racismo e ao desconhecimento da história da cultura africana e afro brasileira e a necessidade de sua superação, em alguns pontos antecipando-se ou indo além do que havia sido definido na legislação federal.

Entretanto, conforme já demonstraram vários estudos, existem grandes distâncias entre o texto legal e as práticas cotidianas. A implementação da legislação, tanto quanto sua constituição e aprovação, pode ser vista como um campo de disputas, no qual distintas intepretações e ações promovem o seu (re)desenho. Essa perspectiva pautou o estudo realizado nas escolas. Nele buscouse analisar as especificidades da ERER com base nas características dos dois contextos.

Observou-se algumas peculiaridades dignas de nota, a primeira delas é o fato de que o supervisor da Escola B é licenciado em História e tem Especialização em Estudos Africanos e Afrobrasileiros. A circunstância de um profissional com essa formação ocupar tal função pode ser interpretada como parte do esforço do grupo em ampliar e aprofundar a ERER, o que não significa 
obviamente que se tenha estabelecido qualquer tipo de consenso em torno da questão, ou que se tenha modificado o "currículo oculto" e superado o "currículo turístico" característico de uma abordagem esporádica e pouco aprofundada da temática. Na Escola $A$ observou-se, além dessas limitações, a formulação de um discurso de impotência que transfere para o âmbito externo - na forma de fiscalização e cobrança por parte da SMED - as expectativas de proposição de atividades e reflexões que não ocorreriam por iniciativa dos professores.

O intrincado contexto dessas escolas, sumariamente apresentado nesse artigo, refletiu-se nas respostas dadas pelos estudantes concluintes do EF ao questionário proposto. Nesse tópico destacaram-se: a manutenção de um conhecimento majoritariamente circunscrito às temáticas do tráfico e da escravidão; a tendência a narrativas vitimizantes ou heroicizantes da população negra; a extrema dificuldade em reconhecer exemplos de participação da população negra na história e na cultura da sociedade brasileira e de problematizar naturalizações arraigadas no senso comum. Por outro lado, observou-se um importante consenso em torno da condenação ao racismo e à discriminação da população negra. Tal consenso pode ser visto como resultado do estabelecimento dessa discussão e como um passo adiante no longo caminho para o estabelecimento de relações étnicoraciais democráticas em nossa sociedade.

\section{REFERÊNCIA DOCUMENTAIS}

1. BRASIL. Presidência da República. Lei $n^{\circ}$ 10.639, de 9 de janeiro de 2003. Disponível em: http://www.planalto.gov.br/ccivil_03/leis/2003/L10.639.htm. Último Acesso em: 03 fev. 2018.

2. INSTITUTO BRASILEIRO DE GEOGRAFIA E ESTATÍSTICA/IBGE, Censo 2010. Disponível em: https://censo2010.ibge.gov.br/ . Último acesso em: 07/06/2018.

3. SÃO LEOPOLDO. Lei $\mathrm{n}^{\circ}$ 6.616, de 18 de dezembro de 2006. Disponível em: https://leismunicipais.com.br/a/rs/s/sao-leopoldo/lei- ordinaria/2006/612/6116. Último Acesso em: 31 jan. 2018.

4. _. Lei $\mathrm{n}^{\circ}$ 6.573, de 24 de março de 2008. Disponível em: https://leismunicipais.com.br/a/rs/s/sao-leopoldo/lei-ordinaria/2008/657/6573/. Último Acesso em: 29 nov. 2017. Conselho Municipal de Educação. Resolução CME/CEINC n0 009, aprovada em 29 de $\begin{array}{llll}\text { setembro de } 2010 . & \text { Disponivel }\end{array}$ https://docs.google.com/file/d/OB6KAQ61pMY4wWk95ai1sQ3A1ZHM/edit Último Acesso em: 31 jan. 2018. 

Secretaria Municipal de Educação. Orientações curriculares para a Educação Básica da Rede Municipal de Educação de São Leopoldo. São Leopoldo: Smed, 2012. Lei $n^{\circ}$ 8.291, de 24 de junho de 2015. Disponível em: <https://leismunicipais.com.br/planomunicipal- de-educacao- sao-leopoldo- rs>. Acesso em: 31 jan. 2016.

\section{REFERÊNCIAS BIBLIOGRÁFICAS}

1. BALL, S.J.; BOWE, R. Subject departments and the "implementation" of National Curriculum policy: an overview of the issues. Journal of Curriculum Studies, London, v. 24, n. 2, p. 97-115, 1992.

2. COELHO, W. N. B; SOARES, N. J. B. Formação continuada e a implementação da $n^{\circ}$ 10.639/2003: diálogos entre Universidade e Escola. Revista da ABPN, [S.I.], v. 8, n. 19, p. 69-96, mar. 2016.

3. GOMES, Nilma Lino (Org.). Práticas pedagógicas de trabalho com relações étnico-raciais na escola na perspectiva da Lei 10.639/2003. Brasília: MEC; Unesco, 2012.

4. GOMES, Nilma Lino. Relações Étnico-Raciais, educação e descolonização dos currículos. Currículo sem Fronteiras, [S.I.], v.12, n.1, p. 98-109, jan./abr. 2012a.

5. GOMES, N. L; JESUS, R. E. As práticas pedagógicas de trabalho com relações étnico-raciais na escola na perspectiva de Lei 10.639/2003: desafios para a política educacional e indagações para a pesquisa. Educar em Revista, Curitiba, n. 47, p. 19-33, jan./mar. 2013.

6. GRIJÓ, W. P; SOUSA, A. H. F. O negro na telenovela brasileira: a representação nas telenovelas da TV Globo na década de 2000. In: CONGRESSO BRASILEIRO DE CIÊNCIAS DA COMUNICAÇÃO, 34, 2-6 set. 2011, p. 1-16.

7. JOHANN, Renata Finkler. Na trama dos escravos de sua majestade: o batismo e as redes de compadrio dos cativos da Real Feitoria do Linho Cânhamo (1788-1798). 2010. 56 f. Trabalho de Conclusão de Curso (Licenciatura em História) - Curso de História, Universidade Federal do Rio Grande do Sul (UFRGS), Porto Alegre, 2010.

8. MAINARDES, Jefferson. Abordagem do ciclo de políticas: uma contribuição para a análise de políticas educacionais. Educação e Sociedade, Campinas, v. 27, n 94, jan./abr. 2006. 
9. MUNANGA, K. (Org.). Superando o racismo na escola. Brasília: Ministério da Educação, 2005.

10. SANTOMÉ, Jurjo Torres. As culturas negadas e silenciadas no currículo. In: SILVA, Tomaz Tadeu da. Alienígenas em sala de aula: uma introdução aos estudos culturais em educação. Petrópolis: Vozes, 2009.

11. SILVA, Petronilha Beatriz Gonçalves. Aprender, ensinar e relações étnico-raciais no Brasil. Educação, Porto Alegre/RS, n. 3 (63), p. 489-506, set./dez. 2007.

12. SILVA, Tomaz Tadeu. O currículo como fetiche: a poética e a política do texto curricular. Belo Horizonte: Autêntica, 1999.

13. Documentos de identidade: uma introdução às teorias do currículo. Belo Horizonte: Autêntica, 2003.

\section{Isabel Bilhão}

Doutora em História pela Universidade Federal do Rio Grande do Sul. Professora do Programa de PósGraduação em Educação da Universidade do Vale do Rio dos Sinos (UNISINOS).

\section{Cátia Silene Morera}

Pedagoga e Mestra em Educação pela Universidade do Vale do Rio dos Sinos (UNISINOS/RS), Professora na Rede Municipal de Ensino de São Leopoldo/RS.

\section{Como citar este documento:}

BILHÃO, Isabel; MORERA, Cátia Silene. A educação das relações étnico-raciais em âmbito escolar: uma análise das concepções de alunos concluintes do ensino fundamental. Reflexão e Ação, Santa Cruz do Sul, v. 26, n. 3, nov. 2018. ISSN 1982-9949. Disponível em: <https://online.unisc.br/seer/index.php/reflex/article/view/11706>. Acesso em: 19 nov. 2018. doi:https://doi.org/10.17058/rea.v26i3.11706. 